\title{
EFFECT OF STRENGTH TRAINING ON PSYCHOPHYSIOLOGICAL ASPECTS IN PARALYMPIC POWERLIFTING ATHLETES: A PILOT STUDY
}

original paper

() Wroclaw University of Health and Sport Sciences

DOI: https://doi.org/10.5114/hm.2022.111391

\section{DONIZETE CHAVES DA SILVA ${ }^{1,2}$, MARCELO DANILLO MATOS DOS SANTOS ${ }^{1,2}{ }^{\circledR}$, FELIPE J. AIDAR ${ }^{3 \oplus}$, BRENO GUILHERME DE ARAÚJO TINOCO CABRAL ${ }^{4 \oplus}$, EDUARDO STIELER $^{1,2 \oplus}$, RENAN ALVES RESENDE ${ }^{1,2}{ }^{\circledR}$, ANDRÉ GUSTAVO PEREIRA DE ANDRADE $^{1,2}{ }^{\circledR}$, PAULO FRANCISCO DE ALMEIDA-NETO ${ }^{4{ }^{\circledR}}$, ALEXANDRE BULHÕES-CORREIA ${ }^{4}{ }^{\circledR}$, RENATO CARVALHO GUERREIRO ${ }^{1,2}{ }^{\oplus}$, MARCO TÚLIO DE MELLO ${ }^{1,2}{ }^{\oplus}$, ANDRESSA DA SILVA $^{1,2}$ \\ ${ }^{1}$ School of Physical Education, Physiotherapy and Occupational Therapy, Federal University of Minas Gerais, Belo Horizonte, Brazil \\ ${ }^{2}$ Sports Training Centre, Federal University of Minas Gerais, Belo Horizonte, Brazil \\ ${ }^{3}$ Centre of Biological and Health Sciences, Physical Education Department, Federal University of Sergipe, São Cristóvão, Brazil \\ ${ }^{4}$ Health Sciences Centre, Physical Education Department, Federal University of Rio Grande do Norte, Natal, Brazil}

\section{ABSTRACT}

Purpose. The study aim was to evaluate the maximum dynamic strength (MDS), mood levels, stress, and recovery during strength training in Paralympic powerlifting (PP).

Methods. The study involved 7 male PP athletes (41.0 \pm 10.1 years; $84.7 \pm 21.1 \mathrm{~kg}$ ). MDS (one-repetition maximum [1RM] with bench press), stress/recovery (RESTQ-Sport), mood status (BRUMS), and resting heart rate (oximeter) were determined before and after a PP training mesocycle (4 weeks). The bench press training was performed with 5 sets of 5 repetitions $(5 \times 5)$ with $80-85 \%$ of $1 \mathrm{RM}$ in the $1^{\text {st }}$ week, $5 \times 3$ with $85-90 \%$ of $1 \mathrm{RM}$ in the $2^{\text {nd }}$ week, $5 \times 1-3$ with $90-95 \%$ of $1 \mathrm{RM}$ in the $3^{\text {rd }}$ week, and $5 \times 5$ with $40-70 \%$ of 1 RM in the $4^{\text {th }}$ week.

Results. There was a significant increase in MDS ( $p<0.001$; effect size [ES]: 0.50). In the RESTQ-Sport scales, lack of energy ( $p<0.022$; ES: 1.30$)$, success ( $p<0.035$; ES: 0.33), and sleep quality $(p<0.007$; ES: 0.62$)$ increased. The scales of general well-being ( $p<0.012$; ES: 2.18), interval disturbances ( $p<0.021$; ES: 3.14), personal acceptance, and self-regulation $(p<0.006$; ES: 2.21) decreased. Regarding mood, the dimensions of tension $(p<0.003$; ES: 1.32), depression $(p<0.001$; ES: 5.00), anger ( $p<0.001$; ES: 4.75), fatigue ( $p<0.002$; ES: 0.72), and confusion $(p<0.002$; ES: 2.09$)$ increased and the vigour decreased ( $p<0.001$; ES: 0.87$)$.

Conclusions. The internal training load can be controlled by psychophysiological indicators in PP.

Key words: Paralympic powerlifting, muscle strength, physiological stress, recovery, mood

\section{Introduction}

Paralympic powerlifting $(\mathrm{PP})$ is a sport that requires muscle strength, with the only discipline being the adapted bench press, so the sport is practised by men and women with physical disabilities in the lower limbs [1]. The sport has aroused interest in a number of participants; thus, it becomes increasingly important to monitor the preparation of athletes, aiming to optimize the results in competitions [2, 3]. In this sense, to max- imize performance, training in PP involves the manipulation of several biodynamic variables, such as volume, intensity, frequency, and density, among others [2, 4-6].

However, the product of this set is classified as external training load, and the organization of these variables contributes to the desired physiological adaptations, which imply an increase in sports performance in PP [7]. On the other hand, the internal training load is considered any psychophysiological response presented by the individual to a given stimulus [6, 8]. An

Correspondence address: Felipe J. Aidar, Centre of Biological and Health Sciences, Physical Education Department, Federal University of Sergipe, Av. Marechal Rondon, s/n, Jd. Rosa Elze, São Cristóvão/SE, 49100-000, Brazil, e-mail: fjaidar@gmail.com, https://orcid.org/0000-0001-7378-4529

Received: April 20, 2021

Accepted for publication: November 26, 2021

Citation: da Silva DC, dos Santos MDM, Aidar FJ, Cabral BGAT, Stieler E, Resende RA, de Andrade AGP, de Almeida-Neto PF, Bulhões-Correia A, Guerreiro RC, de Mello MT, da Silva A. Effect of strength training on psychophysiological aspects in paralympic powerlifting athletes: a pilot study. Hum Mov. 2022;23(3)150-159; doi: https://doi.org/10.5114/hm.2022.111391. 
increase in training loads is necessary to achieve high performance in high-performance sports. However, a balance must be sought between the stress generated by training and recovery; otherwise, many physiological and psychological functions may be affected [9].

Thus, it is necessary to monitor the external and internal training loads during the training periods in PP so that the athlete is considered as a physical and a psychological body that coexist and interact with each other [10]. For Kellmann [11], the control of training can be achieved through the association of psychological and physiological parameters and specific performance. Previous studies have suggested that the stress/ recovery process and mood state, in response to the stimuli generated by training and several factors (i.e., sleep restriction or insufficient nutrient intake, among others), can be controlled through the Recovery-Stress Questionnaire for Athletes (RESTQ-Sport) scales (monitoring of stress and recovery) and the Brunel Mood Scale (BRUMS) (monitoring of mood) in sports [8, 12].

On the other hand, studies focused on PP have addressed issues of heating, biomechanical procedures, as well as the use of supplements, or even the aetiology of injuries [3, 13-20]. However, recovery is a crucial point in sports training [21] and involves load control leading to functional adaptations, preventing and managing stress [22, 23]. In this sense, stress control in training and competition has been achieved by using self-report and questionnaires at virtually no cost to the athlete [11, 24, 25]. Thus, the relationship between stress and recovery tends to impact on performance by interfering with training [26, 27], which points to the need for individualization and load monitoring [28-30]. In addition, individual sports seem to cause more stress [31], interfering even more with recovery [32]. This, associated with high training loads, tends to increase physical and psychological stress [8]. Given the few studies related to the modality and psychosocial indicators [33], the issue implies a problem in PP.

This study therefore aimed to evaluate the maximum dynamic strength (MDS), mood levels, stress, and recovery over a period of strength training in $\mathrm{PP}$ athletes.

\section{Material and methods}

\section{Sample}

The sample consisted of 7 athletes, all male (age: $41.0 \pm 10.1$ years; body mass: $84.7 \pm 21.1 \mathrm{~kg})$. The initial one-repetition maximum (1RM) with the bench press adapted from $96.4 \pm 20.5 \mathrm{~kg}$ was classified by the Brazilian Paralympic Committee. The sample was chosen for convenience and involved 6 athletes with a spinal cord injury below the $8^{\text {th }}$ thoracic vertebra and 1 amputee (transtibial athlete). The participants were recommended to maintain their daily activities, to sleep and eat as usual, not to drink alcohol or caffeine within the 24 hours before the collection of psychophysiological data, and not to perform any other type of physical exercise during the study period. All subjects were informed about the possible benefits and risks of the participation in the study.

\section{Study design}

A randomized study was carried out, in which the participants were allocated in a single group and were submitted to data collection before and after a mesocycle (1 mesocycle corresponds to 4 weeks) of strength training of the modality. Figure 1 depicts the experimental design of the study.

During the collection sessions, the volunteers attended the Brazilian Paralympic Reference Centre of

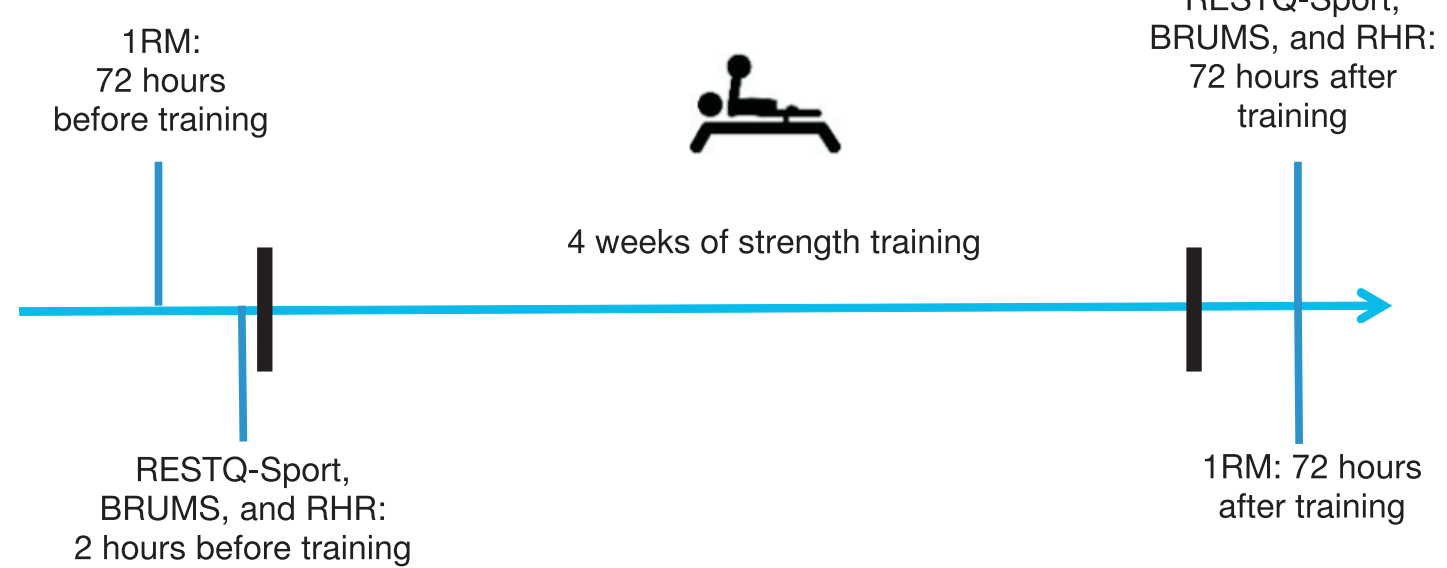

1RM - one-repetition maximum, RESTQ-Sport - Recovery-Stress Questionnaire for Athletes, BRUMS - Brunel Mood Scale, $\mathrm{RHR}$ - resting heart rate 
the Federal University of Minas Gerais in the morning. They filled in a questionnaire concerning personal data, occupation, health history, use of medication, practised sports and other physical activities. In the $1 \mathrm{RM}$ test, the athletes performed a warm-up of 3 exercises for the upper limbs (abduction of the shoulders with dumbbells, shoulder development on a machine, rotation of the shoulders with dumbbells), with 3 sets of 10-20 RM [34].

Then, a specific warm-up was performed with the bench press adapted with $30 \%$ of the load for $1 \mathrm{RM}$. The bench press 1RM tests were conducted 72 hours before the mesocycle and 72 hours after the mesocycle. For the assessment of the psychophysiological data (stress/recovery and mood), the athletes answered the questionnaires in an isolated noise room at an ambient temperature of $25^{\circ}$ at the same time of the day. The collections were performed 2 hours before the mesocycle and 72 hours after the mesocycle (before the 1 RM test). Resting heart rate (RHR) was evaluated in the same time interval.

We highlight, in relation to the data collection period, that according to the coach of the sport, the periodization was done exactly through monthly training cycles, owing to the tight schedule of competitions. Therefore, the training period in which data collection was performed did not suffer the effect of specific moments such as the beginning of the season, pre-competitive and/or competitive period.

\section{Instruments}

The weighing of the athletes was carried out on a digital electronic scale platform (Micheletti ${ }^{\oplus}$, São Paulo, Brazil) with an accuracy of $0.001 \mathrm{~kg}$, a maximum supported capacity of $3000 \mathrm{~kg}$, and a dimension of $1.50 \times 1.50 \mathrm{~m}$. This scales model makes it easy to weigh wheelchair users.

\section{Maximum dynamic strength}

The 1RM test was performed to determine the maximum dynamic strength; thus, each participant started the attempts with a weight that they could lift only once using the maximum effort. Weight increments were then added until the maximum load was reached. The 1RM was determined within a maximum of 6 attempts. If the subject was unable to perform a single repetition, $2.5 \%$ of the load was subtracted [35]. The participants rested for 3-5 minutes between the attempts. The test to determine MDS was conducted 72 hours before the mesocycle and 72 hours after the training mesocycle.

\section{Strength training protocol}

There was a progression in training for 3 weeks so that when the volume (the number of exercises, sets, and repetitions) decreased, the intensity (percentage of $1 \mathrm{RM}$ for bench press) increased. The $4^{\text {th }}$ week involved the taper period, interrelation of volume and intensity, and recovery [36]. The load configuration in this training included recommendations from several systems and techniques used in strength training $[35,37,38]$ in an attempt to increase the maximum strength. The participants trained 3 times a week. In week 1 , they performed 5 sets of 5 repetitions $(5 \times 5)$ using $80-85 \%$ of $1 \mathrm{RM}$ in the bench press and auxiliary exercises with 3 sets of 6 repetitions $(3 \times 6)$ with $70-90 \%$ of $1 \mathrm{RM}$ (bench press $45^{\circ}$, shoulder press, triceps pulley, biceps curl with dumbbells and pronated row). In week 2,5 sets of 3 repetitions $(5 \times 3)$ were performed with $85-90 \%$ of 1RM in the adapted bench press and the same auxiliary exercises as in the previous week. In week 3, 5 sets of up to 3 repetitions $(5 \times 1-3)$ were performed with $90-95 \%$ of $1 \mathrm{RM}$ in the adapted bench press, in addition to the set of auxiliary exercises performed in weeks 1 and 2 . In week 4 , a $5 \times 5$ pattern was applied with $40-70 \%$ of $1 \mathrm{RM}$, without auxiliary exercises [34, 39].

\section{Psychosocial indicators (RESTQ-Sport and BRUMS)}

To assess the athletes' state of stress and recovery in their perception, the RESTQ-Sport was applied before and after the mesocycle. The questionnaire has 19 scales, each containing 4 items distributed throughout the questionnaire. There are 7 general scales of stress (general stress, emotional stress, social stress, conflicts/ pressure, fatigue, lack of energy, and somatic complaints), 5 general scales of recovery (success, social relaxation, somatic relaxation, general well-being, and sleep quality), 3 sports stress scales (interval disturbances, emotional exhaustion, and injuries), and 4 sports recovery scales (being in shape, personal acceptance, self-efficacy, and self-regulation). The questionnaire involves a Likert scale of 0-6, indicating the frequency of occurrence of the given facts, with $0=$ never, $3=$ half the time, and $6=$ always [29, 40-42]. The mood state of the athletes was assessed by applying the BRUMS questionnaire before and after the mesocycle. The instrument contains 6 dimensions, with 4 items each; therefore, it has 24 questions in total. Of the 6 dimensions, 5 have a negative character and 1 has a positive character. The questionnaire employs 
a Likert-type scale of $0-4$, indicating mood-related feelings, with $0=$ nothing, $2=$ moderately, and $4=\mathrm{ex}^{-}$ tremely [43, 44].

\section{Resting heart rate}

For RHR evaluation, the volunteers were asked to sit at rest and in silence, with their back against a chair (for wheelchair users, the wheelchair itself was used) and elbow at $90^{\circ}$ of flexion for 10 minutes. RHR was measured within 10 minutes of rest with a finger pulse oximeter (Nonin Onyx $9500^{\circledR}$, Brazil); the mean value over this time was recorded [45].

\section{Statistical analysis}

The normality of the data was verified by using the Anderson-Darling and $z$-score tests for asymmetry and kurtosis (-1.96 to 1.96). The comparisons between the moments before and after strength training were performed with Student's dependent $t$-test (parametric variables) and the Wilcoxon test (non-parametric variables). The effect size for the differences was calculated with Cohen's $d$ test; the following magnitudes were considered: insignificant $(\leq 0.19)$, small (0.20-0.49), medium (0.50-0.79), large (0.80-1.29), and very large $(\geq 1.30)$ [46]. Correlations were established by using the Spearman test and the magnitudes adopted were those provided by Schober et al. [47]: insignificant $(r<0.10)$, weak $(r$ : 0.10-0.39), moderate $(r: 0.40-0.69)$, strong $(r: 0.70-0.89)$, and very strong ( $r$ : 0.90-1.00). All analyses were performed by using the open-source R software (version 4.0.1; R Foundation for Statistical Computing ${ }^{\oplus}$, Vienna, Austria). The value of $p<0.05$ was considered for statistical significance.

The sampling power of post-hoc analyses was calculated with the open-source $G^{*}$ Power ${ }^{\oplus}$ software (version 3.0; Berlin, Germany); the configuration 'T family statistics' was considered for the difference between 2 dependent means (matched pairs) and correlations. Thus, we used the effects of Cohen's $d$ and Spearman's $r$ found in the results of the present study, and we considered a pattern of $\alpha=0.05$. The sampling power was considered acceptable as $>0.70$ [48].

\section{Ethical approval}

The research related to human use has complied with all the relevant national regulations and institutional policies, has followed the tenets of the Declaration of Helsinki, and has been approved by the Federal University of Minas Gerais Ethics Committee (approval No.: 2.637.882, date of approval: May 7, 2018).

\section{Informed consent}

Informed consent has been obtained from all individuals included in this study.

\section{Results}

As implied in Table 1, MDS increased significantly, and there was no statistically significant difference in RHR during the training period. The results for scales referring to lack of energy, success, and sleep quality after training increased significantly. The scores of general well-being, interval disturbances, personal acceptance, and self-regulation decreased significantly after training. For the other variables analysed, no significant differences were found in the comparisons between the moments before and after strength training.

Concerning the BRUMS scale, the total score pointed to a significant improvement, while the isolated domains of tension, fatigue, mental confusion, depression, and anger increased significantly. Besides, the vigour domain score was reduced significantly (Table 2).

Table 3 shows the correlations between MDS and RHR and the BRUMS and RESTQ-Sport indicators. Both RHR and MDS presented significant correlations with the BRUMS and RESTQ-Sport indicators.

\section{Discussion}

This study aimed to evaluate MDS, mood levels, stress, and recovery over a period of strength training in PP. The main results were: (1) The 4 weeks of strength training contributed to increasing the athletes' performance expressed through MDS. (2) There was a change in the internal training load after the increase in psychological indicators, such as lack of energy, success, and sleep quality, and reduction in the scales of general well-being, interval disturbances, personal acceptance, and self-regulation. (3) Regarding the BRUMS scale, there was an increase in the dimensions of tension, depression, anger, fatigue, and mental confusion; decreased vigour was reported. (4) RHR and MDS showed significant correlations with the BRUMS and RESTQ-Sport indicators.

It is noteworthy that MDS is defined as the force that can be applied only once on a given external resistance [35]. Therefore, the intensity in strength training is extremely important for sports such as powerlifting and PP, in which it is regularly based on the development of maximum strength as the athletes try to lift the heaviest load possible in a maximum repetition [2, 9]. In our study, the 4-week strength training contributed significantly to an increase in MDS of 


\section{HUMAN MOVEMENT}

D.C. da Silva et al., Paralympic powerlifting training

Table 1. Comparisons of the scores for MDS, RESTQ-Sport domains, and RHR before and after strength training

\begin{tabular}{|c|c|c|c|c|c|c|c|c|}
\hline \multirow{2}{*}{ Variables } & \multicolumn{4}{|c|}{ Parametric data (mean $\pm S D$ ) } & \multicolumn{2}{|c|}{ Effect size } & \multirow{2}{*}{$\begin{array}{l}\text { Sample } \\
\text { power }\end{array}$} & \multirow{2}{*}{$p$} \\
\hline & \multicolumn{2}{|c|}{ Before } & \multicolumn{2}{|c|}{ After } & Cohen's $d$ & $95 \% \mathrm{CI}$ & & \\
\hline MDS (Kg) & \multicolumn{2}{|c|}{$96.4 \pm 20.5$} & \multicolumn{2}{|c|}{$107.1 \pm 22.1$} & 0.50 & $0.45 ; 0.55$ & 0.31 & $<0.001^{*}$ \\
\hline Lack of energy & \multicolumn{2}{|c|}{$1.25 \pm 0.24$} & \multicolumn{2}{|c|}{$1.64 \pm 0.36$} & 1.30 & $1.00 ; 0.32$ & 0.91 & $0.02 *$ \\
\hline Success & \multicolumn{2}{|c|}{$3.39 \pm 0.75$} & \multicolumn{2}{|c|}{$3.64 \pm 0.75$} & 0.33 & $0.25 ; 0.38$ & 0.19 & $0.03 *$ \\
\hline Sleep quality & \multicolumn{2}{|c|}{$3.57 \pm 0.75$} & \multicolumn{2}{|c|}{$3.96 \pm 0.51$} & 0.62 & $0.45 ; 0.70$ & 0.42 & $0.007^{*}$ \\
\hline General well-being & \multicolumn{2}{|c|}{$4.25 \pm 0.24$} & \multicolumn{2}{|c|}{$3.75 \pm 0.21$} & 2.18 & $2.05 ; 2.30$ & 0.99 & $0.01 *$ \\
\hline Interval disturbances & \multicolumn{2}{|c|}{$2.46 \pm 0.27$} & \multicolumn{2}{|c|}{$1.86 \pm 0.12$} & 3.14 & $2.50 ; 3.20$ & 1.00 & $0.02 *$ \\
\hline Personal acceptance & \multicolumn{2}{|c|}{$3.93 \pm 0.27$} & \multicolumn{2}{|c|}{$3.29 \pm 0.31$} & 2.18 & $1.80 ; 2.30$ & 0.99 & $0.01^{*}$ \\
\hline Self-regulation & \multicolumn{2}{|c|}{$4.11 \pm 0.55$} & \multicolumn{2}{|c|}{$3.32 \pm 0.32$} & 2.21 & $1.40 ; 2.50$ & 0.99 & $0.006^{*}$ \\
\hline General stress & \multicolumn{2}{|c|}{$1.11 \pm 0.24$} & \multicolumn{2}{|c|}{$1.39 \pm 0.14$} & -1.50 & $-1.00 ;-2.00$ & 0.96 & 0.06 \\
\hline Emotional stress & \multicolumn{2}{|c|}{$1.25 \pm 0.14$} & \multicolumn{2}{|c|}{$1.36 \pm 0.30$} & 0.23 & $0.25 ; 0.25$ & 0.13 & 0.6 \\
\hline Social stress & \multicolumn{2}{|c|}{$1.25 \pm 0.50$} & \multicolumn{2}{|c|}{$1.25 \pm 0.43$} & 0.79 & $0.55 ; 0.85$ & 0.58 & 1.0 \\
\hline Conflicts/pressure & \multicolumn{2}{|c|}{$2.61 \pm 1.46$} & \multicolumn{2}{|c|}{$2.32 \pm 0.72$} & 0.26 & $0.20 ; 0.30$ & 0.15 & 0.5 \\
\hline Fatigue & \multicolumn{2}{|c|}{$2.14 \pm 0.82$} & 2.25 & 0.41 & -0.17 & $-0.10 ;-0.20$ & 0.10 & 0.7 \\
\hline Somatic complaints & $1.75 \pm$ & 0.71 & 1.57 & 0.31 & 0.35 & $0.20 ; 0.38$ & 0.20 & 0.5 \\
\hline Social relaxation & $3.54 \pm$ & 0.75 & 3.54 & 0.39 & 0.25 & $0.18 ; 0.35$ & 0.14 & 0.7 \\
\hline Somatic relaxation & $3.14 \pm$ & 0.31 & 3.57 & 0.20 & -1.68 & $-0.50 ;-1.80$ & 0.98 & 0.1 \\
\hline Emotional exhaustion & $1.46 \pm$ & 0.61 & 1.32 & 0.32 & 0.31 & $0.20 ; 0.45$ & 0.18 & 0.6 \\
\hline Injuries & $2.50 \pm$ & 0.78 & 2.07 & 0.43 & 0.71 & $0.65 ; 0.80$ & 0.50 & 0.1 \\
\hline Being in shape & $3.54 \pm$ & .47 & 3.25 & 0.24 & 0.80 & $0.70 ; 0.87$ & 0.60 & 0.4 \\
\hline Self-efficacy & $3.79 \pm$ & 0.27 & 3.29 & 0.20 & 2.10 & $1.70 ; 2.50$ & 0.99 & 0.06 \\
\hline & & iparan & tric da & & & & & \\
\hline & $\mathrm{M}$ & IQI & M & IQI & & & & \\
\hline RHR (bpm) & 80.0 & 5.00 & 83.0 & 6.00 & 0.01 & $-0.11 ; 0.03$ & 0.05 & 0.467 \\
\hline
\end{tabular}

MDS - maximum dynamic strength, RESTQ-Sport - Recovery-Stress Questionnaire for Athletes, RHR - resting heart rate, $\mathrm{M}$ - median, IQI - interquartile interval

* statistically significant

Table 2. Comparisons of the BRUMS domain variables before and after strength training

\begin{tabular}{|c|c|c|c|c|c|c|c|c|}
\hline \multirow{2}{*}{ Variables } & \multicolumn{4}{|c|}{ Parametric data (mean $\pm S D$ ) } & \multicolumn{2}{|c|}{ Effect size } & \multirow{2}{*}{$\begin{array}{c}\text { Sample } \\
\text { power }\end{array}$} & \multirow{2}{*}{$p$} \\
\hline & \multicolumn{2}{|c|}{ Before } & \multicolumn{2}{|c|}{ After } & Cohen's $d$ & $95 \% \mathrm{CI}$ & & \\
\hline BRUMS & \multicolumn{2}{|c|}{$0.76 \pm 0.27$} & \multicolumn{2}{|c|}{$1.07 \pm 0.79$} & 3.12 & $2.70 ; 3.15$ & 1.00 & $0.001^{*}$ \\
\hline Tension & \multicolumn{2}{|c|}{$0.68 \pm 0.29$} & \multicolumn{2}{|c|}{$1.11 \pm 0.36$} & -1.32 & $-1.00 ;-1.35$ & 0.92 & $0.003^{*}$ \\
\hline Fatigue & \multicolumn{2}{|c|}{$0.68 \pm 0.29$} & \multicolumn{2}{|c|}{$0.86 \pm 0.20$} & -0.72 & $-0.60 ;-0.78$ & 0.51 & $0.002 *$ \\
\hline \multirow[t]{3}{*}{ Mental confusion } & \multicolumn{2}{|c|}{$0.32 \pm 0.14$} & \multicolumn{2}{|c|}{$0.89 \pm 0.41$} & -2.09 & $-1.75 ;-2.15$ & 0.99 & $0.002 *$ \\
\hline & \multicolumn{4}{|c|}{ Nonparametric data } & & & & \\
\hline & M & IQI & M & IQI & & & & \\
\hline Depression & 0.29 & 0.00 & 0.71 & 0.15 & -5.00 & $-4.37 ;-5.05$ & 1.00 & $<0.001^{*}$ \\
\hline Anger & 0.00 & 0.00 & 0.64 & 0.40 & -4.75 & $-4.00 ;-5.00$ & 1.00 & $<0.001^{*}$ \\
\hline Vigour & 2.86 & 1.10 & 2.29 & 1.40 & 0.87 & $0.67 ; 0.91$ & 0.70 & $<0.001^{*}$ \\
\hline
\end{tabular}

BRUMS - Brunel Mood Scale, M - median, IQI - interquartile interval

* statistically significant 
Table 3. Correlation between RHR and MDS with RESTQ-Sport domains and BRUMS scale

\begin{tabular}{|c|c|c|c|c|}
\hline \multirow{2}{*}{ Indicator } & \multicolumn{2}{|c|}{ Effect size } & \multirow{2}{*}{ Sample power } & \multirow{2}{*}{$p$} \\
\hline & Spearman's $r$ & $95 \% \mathrm{CI}$ & & \\
\hline RHR $\times$ BRUMS & 0.66 & $0.60 ; 0.70$ & 0.46 & 0.03 \\
\hline RHR $\times$ general stress & 0.40 & $0.35 ; 0.45$ & 0.40 & 0.001 \\
\hline RHR $\times$ general recovery & -0.47 & $-0.40 ;-0.50$ & 0.29 & 0.04 \\
\hline RHR $\times$ sports stress & 0.14 & $0.07 ; 0.18$ & 0.09 & 0.002 \\
\hline RHR $\times$ sports recovery & -0.12 & $-0.05 ;-0.15$ & 0.08 & 0.03 \\
\hline MDS $\times$ BRUMS & 0.54 & $0.52 ; 0.60$ & 0.35 & 0.0005 \\
\hline MDS $\times$ general stress & 0.63 & $0.57 ; 0.65$ & 0.43 & 0.001 \\
\hline MDS $\times$ general recovery & -0.60 & $-0.55 ;-0.65$ & 0.40 & 0.01 \\
\hline MDS $\times$ sports stress & 0.68 & $0.62 ; 0.70$ & 0.48 & 0.04 \\
\hline MDS $\times$ sports recovery & -0.10 & $-0.01 ;-0.12$ & 0.07 & 0.003 \\
\hline
\end{tabular}

RHR - resting heart rate, MDS - maximum dynamic strength, RESTQ-Sport - Recovery-Stress Questionnaire for Athletes, BRUMS - Brunel Mood Scale

the analysed subjects. According to Allegretti João et al. [49], the rapid increase in muscle strength related to the systematization of strength training can be explained by the specific neuromuscular adaptations caused by exercise-induced stress within the central nervous system, which results from an increased frequency of firing nerve impulses, as well as recruitment and synchronization of increasingly large specific motor units.

As indicated by Matos Dos Santos et al. [18], MDS is the main physical capacity in PP, and its change is related to the training method and the biomechanics of exercise execution. On the other hand, MDS has also been the target of the load-speed relationship for sports training prescription [14]. In the present study, the stress generated by the 4 -week training period increased the RESTQ-Sport scores, indicating lack of energy, success, and sleep quality after the intervention. The scales of general well-being, interval disturbances, personal acceptance, and self-regulation decreased significantly. Besides, the general stress scale showed an upward trend, while the self-efficacy scale exhibited a downward trend, with a very large effect size for the last 2 scales mentioned. For Almeida Monteiro de Moraes et al. [12], the accumulation of training overload associated with energy restriction indicates deleterious changes in the balance of stress and recovery in strength sports athletes in the pre-competitive period. In this study, the evaluation was free from the competition period. However, despite the relative negative changes in the psychological indicators caused by overload, there is evidence that the use of progressive overload is part of training in PP, as well as in other types of strength training, contributing to an increase in strength, muscle mass, and performance [2, 49]. Nevertheless, even though the progressive overload used in PP strength training is necessary, there is a possibility of generating psychological and physical stress in athletes. According to Fraga et al. [17], 5 sets of 5 repetitions at $85-95 \%$ of $1 \mathrm{RM}$ was enough to generate muscle damage in PP athletes.

Studies carried out with volleyball, rowing, and bodybuilding have shown that with an abrupt increase in the training load, the state of stress/recovery can be impaired; thus, the athletes presented high stress and low recovery $[12,50,51]$. In contrast, with a decrease in load, the opposite occurs: low stress and high recovery [8]. It is therefore believed that the positive psychological responses to training depend on the interrelationship between volume, intensity, and rest during the training period. The evaluation in our study was carried out over a period of progressive loading of the athletes' training. According to Almeida Monteiro de Moraes et al. [12], the imbalance between stress and recovery in the face of overload in strength training, verified through psychological indicators, must be interpreted with caution, the association of biochemical signals, such as creatine kinase, which reinforces the idea that individuals poorly recovered of the training demands with an insufficient rest period. In this sense, it is assumed that the use of questionnaires to control stress/recovery in the context of training becomes subjective, hence the need arises to obtain other parameters for evaluation, unless familiarization with the instrument is frequent $[12,52]$.

In contrast, the post-training sleep quality significantly increased, a fact that is associated with the contribution to the stress/recovery process and athletes' 
performance [53]. Despite this, the sports stress scales, as well as the sports recovery were lower after the training when compared with the baseline level. In addition to training, it is supposed that extra training factors (i.e., sleep, food, interpersonal relationships, and safety) can also influence the psychophysiological status of athletes [7]. However, the assessment of the internal training load must be based on psychological and physiological indicators, as physiological mechanisms can mediate psychological responses in a training process $[8,54]$. In this study, we focused on evaluating the stress generated by training through psychological indicators owing to the practicality of the instruments; however, more sensitive physiological indicators have been used to control internal training load in PP, according to Fraga et al. [17], creatine kinase and lactate dehydrogenase to control muscle damage in a training session, as well as dry needling and immersion in ice water as recovery techniques in PP [55].

Adverse psychological effects have been observed, as revealed in the state of mood, during a period of training in athletes of strength sport [10]. In the present study, the scores in the dimensions of tension, depression, anger, fatigue, and mental confusion increased significantly after training. In turn, vigour decreased significantly. The profile in the form of an iceberg is known when the positive dimension appears with the highest values, and the negative dimensions appear with low values, with the scores differing from the average of the general population [56]. In our study, this profile decreased, indicating changes in mood after training. According to Helms et al. [57], the stress generated by training associated with impaired macronutrient intake negatively altered the mood state of weightlifters.

However, high-performance athletes without mood disorders, when assessed by using the BRUMS scale in a specific training period, reveal a profile in the form of an iceberg [10]. Through the change in mood during 12 months of preparation of bodybuilding athletes, the authors observed that 2 months before the competition, the scores of the emotional scales of tension, anxiety, and anger decreased, a fact associated with the athletes' satisfaction with the training and excitement phase for the competition; in contrast, an increase in the fatigue and tension-anxiety scales scores, and a decrease in the vigour scale score were also observed in the pre-competitive period, negatively altering the athletes' state of vigour. In our study, the pre-training vigour dimension result was above the $60^{\text {th }}$ percentile; however, after the training, it was below this benchmark. All negative dimensions scored below the $40^{\text {th }}$ percentile at both times, which contributes to the iceberg profile of PP athletes. Adverse changes in mood after training may have been associated with the progressive overload in this period.

In this context, the mood state has also been influenced by extra training factors, such as sleep disturbance and restriction, macronutrient restriction, a rapid loss of body mass, among others [10, 53]. Thus, the acute or chronic evaluation of training in PP, as well as in other strength training sports, must involve psychophysiological responses; for the accuracy of these variables, questionnaires and blood and salivary samples should be used [12, 51]. Besides, RHR has been applied as a physiological indicator in the control of exercise intensity [58], the use of this marker is part of the control of the internal training load in strength training sports such as powerlifting and PP [2, 39].

In the present study, there was no statistically significant difference in post-training RHR. Training sessions with loads $>80 \%$ of $1 \mathrm{RM}$ contribute to an increase in RHR, which appears to be caused by a reduction in cardiac output mediated by stroke volume [58]. In summary, the change in RHR concerning high training loads in powerlifting is related to an increase in sympathetic activity and reduction of parasympathetic activity in the heart [39]. In our study, the loads ranged $40-95 \%$ of $1 \mathrm{RM}$; however, there was no change after the training period. De Almeida Paz et al. [2] compared 2 different sessions of strength training, $5 \times 5$ with $80-85 \%$ of $1 \mathrm{RM}$ and $5 \times 3$ with $90-95 \%$ of $1 \mathrm{RM}$, and verified the hemodynamic responses in PP. The authors reported that the different protocols increased RHR after the training session but the values quickly returned to baseline within 50 minutes after training for both sessions. In this study, RHR was measured 72 hours after the session; therefore, it is believed that this physiological indicator can be used at both times to control the intensity of strength training in PP.

In our study, RHR and MDS exhibited significant correlations with the BRUMS and RESTQ-Sport indicators. These findings suggest that the psychophysiological variables are related to the specific performance of PP athletes, which corroborates the observations by Impellizzeri et al. [7], who state that external training stimuli will generate an internal physiological and psychological response, which may influence the athlete's perception of the environment, affecting such factors as sleep quality and mood. Thus, it is suggested that in sports training, athletes are seen as multifactorial beings, composed of physical, psychological, and sentimental parts [7, 10]. 
Thus, although there is a gap in studies monitoring internal training load during a period in PP, we obtained interesting results, such as an increase in MDS, positive and negative changes in the dimensions of stress/recovery and mood through the application of the RESTQ-Sport and BRUMS instruments, as well as no alteration of RHR during a period of progressive loading. There were some limitations to the study design used, such as a small sample size and the lack of more sensitive physiological indicators.

\section{Practical applications}

The scales of the RESTQ-Sport and BRUMS questionnaires and the RHR have been widely used to monitor the internal load through the psychophysiological responses of stress, recovery, mood, and heart rate of athletes. The ease, accuracy, and validity of these tools contribute to their applicability among coaches and researchers. Additionally, the relationship of the external load with the control of internal training load can be used to train athletes, as long as this association is familiarized. Therefore, our results suggest that the control of the external training load contributes to significant gains in maximum muscle strength; however, let us assume that an isolated action should not be performed. Therefore, the present study supports the use of internal training load control through RESTQSport, BRUMS, and RHR to monitor individual responses during the prescription of the training load for PP athletes.

\section{Conclusions}

It is concluded that psychophysiological indicators (internal training load) combined with the specific performance of PP athletes can be related to the external training load to assist technicians and sports professionals in the load prescription and sports performance monitoring among PP athletes.

\section{Acknowledgements}

The authors thank for the support given by Pro-Reitoria de Pesquisa (PRPq) - Federal University of Minas Gerais, Conselho Nacional de Desenvolvimento Científico e Tecnológico (CNPq), Fundação de Amparo à Pesquisa do Estado de Minas Gerais (FAPEMIG), Coordenação de Aperfeiçoamento de Pessoal de Nível Superior (CAPES), Secretaria Especial do Esporte do Ministério da Cidadania (Governo Federal, Brasília, Brazil; protocol No.: 58000.008978/2018-37 and 71000.056251/ 2020-49), Comitê Paralímpico Brasileiro (CPB), Cen- tro de Treinamento Esportivo (CTE/EEFFTO/UFMG, FEPE-UFMG), Fundação de Apoio ao Ensino, Pesquisa e Extensão, Centro de Estudos em Psicobiologia e Exercício (CEPE), and Grupo de Estudo e Pesquisa em Performance, Paradesporto e Saúde (GPEPS).

\section{Disclosure statement}

No author has any financial interest or received any financial benefit from this research.

\section{Conflict of interest}

The authors state no conflict of interest.

\section{References}

1. World Para Powerlifting. History of para powerlifting. Available from: https://www.paralympic.org/powerlifting/about.

2. De Almeida Paz Â, Aidar FJ, de Matos DG, de Souza RF, da Silva-Grigoletto ME, van den Tillaar R, et al. Comparison of post-exercise hypotension responses in Paralympic powerlifting athletes after completing two bench press training intensities. Medicina. 2020;56(4):156; doi: 10.3390/medicina56040156.

3. Willick SE, Cushman DM, Blauwet CA, Emery C, Webborn N, Derman W, et al. The epidemiology of injuries in powerlifting at the London 2012 Paralympic Games: an analysis of 1411 athlete-days. Scand J Med Sci Sports. 2016;26(10):1233-1238; doi: 10.1111/sms.12554.

4. Bird SP, Tarpenning KM, Marino FE. Designing resistance training programmes to enhance muscular fitness: a review of the acute programme variables. Sports Med. 2005;35(10):841-851; doi: 10.2165/00007256-20053510000002.

5. Santos MD, Oliveira Barros G, Almeida Barros N, Alejo AA, dos Santos Silva D, Aidar FJ. Anxiety analysis in paralympic weightlifting related to tape [in Portuguese]. Motricidade. 2018;14(1):300-304.

6. Martorelli AS, De Lima FD, Vieira A, Tufano JJ, Ernesto $\mathrm{C}$, Boullosa D, et al. The interplay between internal and external load parameters during different strength training sessions in resistance-trained men. Eur J Sport Sci. 2021;21(1):16-25; doi: 10.1080/17461391.2020. 1725646.

7. Impellizzeri FM, Marcora SM, Coutts AJ. Internal and external training load: 15 years on. Int J Sports Physiol Perform. 2019;14(2):270-273; doi: 10.1123/ijspp.2018-0935.

8. Nunes JA, Moreira A, Crewther BT, Nosaka K, Viveiros L, Aoki MS. Monitoring training load, recovery-stress state, immune-endocrine responses, and physical performance in elite female basketball players during a periodized training program. J Strength Cond Res. 2014;28(10):2973-2980; doi: 10.1519/JSC.00000000 00000499.

9. Ferland P-M, Comtois AS. Classic powerlifting performance: a systematic review. J Strength Cond Res. 2019; 
33(Suppl. 1):S194-S201; doi: 10.1519/JSC.00000000 00003099.

10. Rossow LM, Fukuda DH, Fahs CA, Loenneke JP, Stout JR. Natural bodybuilding competition preparation and recovery: a 12-month case study. Int J Sports Physiol Perform. 2013;8(5):582-592; doi: 10.1123/ ijspp.8.5.582.

11. Kellmann M. Preventing overtraining in athletes in highintensity sports and stress/recovery monitoring. Scand J Med Sci Sports. 2010;20(Suppl. 2):95-102; doi: 10.1111/j.1600-0838.2010.01192.x.

12. Almeida Monteiro de Moraes WM, Carmo de Moura F, da Costa Moraes TC, Oliveira de Sousa LG, Dos Santos Rosa T, Schoenfeld BJ, et al. Oxidative stress, inflammation, psychological status, and severity of respiratory infections are negatively affected during the precontest period in amateur bodybuilders. Appl Physiol Nutr Metab. 2019;44(5):468-476; doi: 10.1139/apnm2018-0430.

13. Gołaś A, Zwierzchowska A, Maszczyk A, Wilk M, Stastny P, Zając A. Neuromuscular control during the bench press movement in an elite disabled and ablebodied athlete. J Hum Kinet. 2017;60:209-215; doi: 10.1515/hukin-2017-0110.

14. Loturco I, Pereira LA, Winckler C, Santos WL, Kobal R, McGuigan M. Load-velocity relationship in national Paralympic powerlifters: a case study. Int J Sports Physiol Perform. 2019;14(4):531-535; doi: 10.1123/ ijspp.2018-0452.

15. De Aquino Resende M, Vasconcelos Resende RB, Costa Reis G, de Oliveira Barros L, Silva Bezerra MR, de Matos DG, et al. The influence of warm-up on body temperature and strength performance in Brazilian national-level Paralympic powerlifting athletes. Medicina. 2020;56(10):538; doi: 10.3390/medicina56100538.

16. Soares Freitas Sampaio CR, Aidar FJ, Ferreira ARP, Dos Santos JL, Marçal AC, de Matos DG, et al. Can creatine supplementation interfere with muscle strength and fatigue in Brazilian national level Paralympic powerlifting? Nutrients. 2020;12(9):2492; doi: 10.3390/ nu12092492.

17. Fraga GS, Aidar FJ, Matos DG, Marçal AC, Santos JL, Souza RF, et al. Effects of ibuprofen intake in muscle damage, body temperature and muscle power in Paralympic powerlifting athletes. Int J Environ Res Public Health. 2020;17(14):5157; doi: 10.3390/ijerph17145157.

18. Matos Dos Santos MD, Aidar FJ, de Souza RF, Lopes Dos Santos J, da Silva de Mello A, Neiva HP, et al. Does the grip width affect the bench press performance of Paralympic powerlifters? Int J Sports Physiol Perform. 2020;15(9):1252-1259; doi: 10.1123/ijspp.2019-0784.

19. Szafraniec R, Kisilewicz A, Kumorek M, Kristiansen M, Madeleine P, Mroczek D. Effects of high-velocity strength training on movement velocity and strength endurance in experienced powerlifters with cerebral palsy. J Hum Kinet. 2020;73:235-243; doi: 10.2478/hukin-20200009.
20. Ribeiro Neto F, Dorneles JR, Luna RM, Spina MA, Gonçalves CW, Gomes Costa RR. Performance differences between the arched and flat bench press in beginner and experienced Paralympic powerlifters. J Strength Cond Res. 2020; doi: 10.1519/JSC.0000000 000003736.

21. Kellmann M, Bertollo M, Bosquet L, Brink M, Coutts AJ, Duffield R, et al. Recovery and performance in sport: consensus statement. Int J Sports Physiol Perform. 2018;13(2):240-245; doi: 10.1123/ijspp.2017-0759.

22. Heidari J, Beckmann J, Bertollo M, Brink M, Kallus KW, Robazza C, et al. Multidimensional monitoring of recovery status and implications for performance. Int J Sports Physiol Perform. 2019;14(1):2-8; doi: 10.1123/ ijspp.2017-0669.

23. Lope Fernández DE, Solís Briceño OB. Coping strategies as stress intervention in soccer players [in Spanish]. Retos. 2020;38:613-619; doi: 10.47197/retos.v38i38. 75724.

24. Halson SL. Monitoring training load to understand fatigue in athletes. Sports Med. 2014;44(Suppl. 2): 139-147; doi: 10.1007/s40279-014-0253-z.

25. Nässi A, Ferrauti A, Meyer T, Pfeiffer M, Kellmann M. Psychological tools used for monitoring training responses of athletes. Perform Enhanc Health. 2017;5(4): 125-133; doi: 10.1016/j.peh.2017.05.001.

26. Reynoso-Sánchez LF, Hernández-Cruz G, LópezWalle J, Rangel-Colmenero B, Quezada-Chacón J-T, Jaenes Sánchez JC. Recovery-stress balance throughout a season in volleyball university players [in Spanish]. Retos. 2016;30:193-197; doi: 10.47197/RETOS.V0I30. 50244.

27. Vacher P, Nicolas M, Martinent G, Mourot L. Changes of swimmers' emotional states during the preparation of national championship: do recovery-stress states matter? Front Psychol. 2017;8:1043; doi: 10.3389/fpsyg.2017.01043.

28. Di Fronso S, Nakamura FY, Bortoli L, Robazza C, Bertollo M. Stress and recovery balance in amateur basketball players: differences by gender and preparation phase. Int J Sports Physiol Perform. 2013;8(6):618622; doi: 10.1123/ijspp.8.6.618.

29. Kellmann M, Kallus KW. Recovery-Stress Questionnaire for Athletes: user manual. Champaign: Human Kinetics; 2001.

30. Brandt R, Bevilacqua GG, Andrade A. Perceived sleep quality, mood states, and their relationship with performance among Brazilian elite athletes during a competitive period. J Strength Cond Res. 2017;31(4):10331039; doi: 10.1519/JSC.0000000000001551.

31. Garinger LM, Chow GM, Luzzeri M. The effect of perceived stress and specialization on the relationship between perfectionism and burnout in collegiate athletes. Anxiety Stress Coping. 2018;31(6):714-727; doi: 10.1080/10615806.2018.1521514.

32. Nixdorf I, Frank R, Beckmann J. Comparison of athletes' proneness to depressive symptoms in individual 
and team sports: research on psychological mediators in junior elite athletes. Front Psychol. 2016;7:893; doi: 10.3389/fpsyg.2016.00893.

33. Roy A. Socio-cultural power dynamics and coping functions: a narrative case report of a female Paralympian. Asian J Sports Med. 2012;3(2):131-138; doi: 10.5812/ asjsm.34715.

34. Austin D, Mann B. Powerlifting. Champaign: Human Kinetics; 2012.

35. Fleck SJ, Kraemer WJ. Designing resistance training programs, $4^{\text {th }}$ ed. Champaign: Human Kinetics; 2004.

36. Grgic J, Mikulic P. Tapering practices of Croatian openclass powerlifting champions. J Strength Cond Res. 2017; 31(9):2371-2378; doi: 10.1519/JSC.000000000000 1699.

37. Wendler J. 5/3/1 for powerlifting: simple and effective training for maximal strength. Jim Wendler LLC; 2011.

38. Simmons L. Westside Barbell book of methods. Columbus: Westside Barbell; 2007.

39. Allegretti João G, Sales Bocalini D, Rodriguez D, Charro MA, Ceschini F, Martins A, et al. Powerlifting sessions promote significant post-exercise hypotension. Rev Bras Med Esporte. 2017;2(23):118-122; doi: 10.1590/1517-869220172302166667.

40. Kellmann M. The relationships between the Recovery-Stress Questionnaire for Athletes and the profile of mood states [in German]. In: Alfermann D, Stoll O (eds.), Motivation and volition in sport: from planning to action [in German]. Köln: bps; 1999; 208-212.

41. Kellmann M, Kallus KW. The Recovery-Stress Questionnaire for Athletes: manual. Frankfurt: Swets Test Services; 2000.

42. Costa LOP, Samulski DM. Validation process of the Recovery-Stress Questionnaire for Athletes (RESTQSport) in Portuguese [in Portuguese]. Rev Bras Cienc Mov. 2005;13(1):79-86.

43. McNair DM, Lorr M, Droppleman LF. Manual for the profile of mood states. San Diego: Educational and Industrial Testing Services; 1971.

44. De Miranda Rohlfs ICP, Rotta TM, Di Bernardi Luft C, Andrade A, Krebs RJ, de Carvalho T. Brunel Mood Scale (BRUMS): an instrument for early detection of overtraining syndrome [in Portuguese]. Rev Bras Med Esporte. 2008;3(14):176-181; doi: 10.1590/S1517-8692 2008000300003.

45. Torre-Bouscoulet L, Chávez-Plascencia E, VázquezGarcía JC, Pérez-Padilla R. Precision and accuracy of “a pocket” pulse oximeter in Mexico City [in Spanish]. Rev Invest Clin. 2006;58(1):28-33.

46. Espirito-Santo H, Daniel F. Calculating and reporting effect sizes on scientific papers (2): guide to report the strength of relationships [in Portuguese]. Rev Port Invest Comp Soc. 2017;3(1):53-64; doi: 10.7342/ismt. rpics.2017.3.1.48.

47. Schober P, Boer C, Schwarte LA. Correlation coefficients: appropriate use and interpretation. Anesth Analg. 2018; 126(5):1763-1768; doi: 10.1213/ANE.000000000000 2864 .
48. Sounis E. Biostatistics: fundamental principles, statistical methodology. Application to biological sciences [in Portuguese]. São Paulo: McGraw-Hill do Brasil; 1971.

49. Allegretti João GA, Lopes Evangelista A, Gomes JH, Charro MA, Bocalini D, Cardozo D, et al. Effect of 16 weeks of periodized resistance training on strength gains of powerlifting athletes. J Exerc Physiol Online. 2014;17(3):102-109.

50. Mäestu J, Jürimäe J, Kreegipuu K, Jürimäe T. Changes in perceived stress and recovery during heavy training in highly trained male rowers. Sport Psychol. 2006; 20(1):24-39; doi: 10.1123/tsp.20.1.24.

51. Horta TAG, Bara Filho MG, Coimbra DR, Miranda R, Werneck FZ. Training load, physical performance, biochemical markers, and psychological stress during a short preparatory period in Brazilian elite male volleyball players. J Strength Cond Res. 2019;33(12):33923399; doi: 10.1519/JSC.0000000000002404.

52. Jones CM, Griffiths PC, Mellalieu SD. Training load and fatigue marker associations with injury and illness: a systematic review of longitudinal studies. Sports Med. 2017;47(5):943-974; doi: 10.1007/s40279-016-0619-5.

53. Alves ES, Pereira Rosa J, de Mello MT. Different intensities of physical exercise on psychological aspects in paraplegic athletes [in Portuguese]. Rev Bras Prescr Fisiol Exerc. 2019;13(83):434-443.

54. Gleeson M. Biochemical and immunological markers of over-training. J Sports Sci Med. 2002;1(2):31-41.

55. Dos Santos WYH, Aidar FJ, de Matos DG, Van den Tillaar R, Marçal AC, Fernandes Lobo L, et al. Physiological and biochemical evaluation of different types of recovery in national level Paralympic powerlifting. Int J Environ Res Public Health. 2021;18(10):5155; doi: 10.3390/ijerph18105155.

56. Meeusen R, Duclos M, Foster C, Fry A, Gleeson M, Nieman D, et al. Prevention, diagnosis and treatment of the overtraining syndrome: joint consensus statement of the European College of Sport Science (ECSS) and the American College of Sports Medicine (ACSM). Eur J Sport Sci. 2013;13(1):1-24; doi: 10.1080/174 61391.2012.730061.

57. Helms ER, Zinn C, Rowlands DS, Naidoo R, Cronin J. High-protein, low-fat, short-term diet results in less stress and fatigue than moderate-protein moderate-fat diet during weight loss in male weightlifters: a pilot study. Int J Sport Nutr Exerc Metab. 2015;25(2):163-170; doi: 10.1123/ijsnem.2014-0056.

58. Corrêa De Sousa E, Abrahin O, Lima Ferreira AL, Pequeno Rodrigues R, Cortinhas Alves EA, Vieira RP. Resistance training alone reduces systolic and diastolic blood pressure in prehypertensive and hypertensive individuals: meta-analysis. Hypertens Res. 2017;40(11): 927-931; doi: 10.1038/hr.2017.69. 